\title{
Binding Behavior of Carbonmonoxide to Gold Atoms on Ag(001)
}

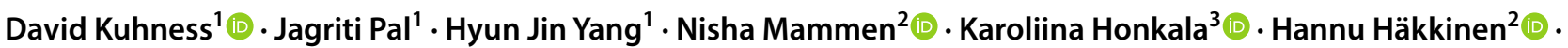 \\ Wolf-Dieter Schneider ${ }^{1}\left[\right.$ [Darkus Heyde ${ }^{1}$ (i) $\cdot$ Hans-Joachim Freund ${ }^{1}[0$
}

Published online: 20 June 2020

(c) The Author(s) 2020

\begin{abstract}
The adsorption behavior of single $\mathrm{CO}$ molecules at $4 \mathrm{~K}$ bound to Au adatoms on a $\mathrm{Ag}(001)$ metal surface is studied with scanning tunneling microscopy (STM) and inelastic electron tunneling spectroscopy (IETS). In contrast to earlier observations two different binding configurations are observed - one on top of a Au adatom and the other one adsorbed laterally to $\mathrm{Au}$ on $\mathrm{Ag}(001)$. Moreover, IETS reveals different low-energy vibrational energies for the two binding sites as compared to the one for a single CO molecule bound to $\operatorname{Ag}(001)$. Density functional theory (DFT) calculations of the adsorption energies, the diffusion barriers, and the vibrational frequencies of the $\mathrm{CO}$ molecule on the different binding sites rationalize the experimental findings.
\end{abstract}

Keywords $\mathrm{CO} \cdot \mathrm{Au} \cdot \mathrm{Ag}(001) \cdot$ Adsorption $\cdot \mathrm{STM} \cdot \mathrm{STS} \cdot \mathrm{IETS} \cdot \mathrm{DFT}$

\section{Introduction}

One of the initial steps in a heterogeneous catalytic reaction is the binding of molecules to surfaces. Characterizing the chemical nature of the molecules as they bind to metal surfaces or model systems involving oxide supported metal nanoparticles is a key issue. Infrared spectroscopy among other techniques is the tool often used [1-7]. However, if characterization via ensemble averaging is not sufficient, and characterization at the individual molecule level is necessary, one has to resort to other techniques. A technique that has proven very useful in this respect is inelastic electron tunneling spectroscopy, IETS [8-11]. Here we study the adsorption of $\mathrm{CO}$ on or near $\mathrm{Au}$ atoms supported on a $\operatorname{Ag}(001)$ surface [12-16].

Electronic supplementary material The online version of this article (https://doi.org/10.1007/s11244-020-01290-3) contains supplementary material, which is available to authorized users.

Markus Heyde

heyde@fhi-berlin.mpg.de

1 Fritz-Haber-Institut der Max-Planck-Gesellschaft, Faradayweg 4-6, 14195 Berlin, Germany

2 Department of Physics, Nanoscience Center, University of Jyväskylä, 40014 Jyväskylä, Finland

3 Department of Chemistry, Nanoscience Center, University of Jyväskylä, 40014 Jyväskylä, Finland
The binding behaviour of $\mathrm{CO}$, representing a prototype molecule, to various metal substrates has been intensively studied in the past. Nevertheless, it is still of interest to many applied experiments like the AgAu alloy catalysts for selective oxidation reactions [17-19].

Of considerable significance for the present investigation of the $\mathrm{CO}$ binding behaviour to individual $\mathrm{Au}$ atoms on $\mathrm{Ag}(001)$ are the reports concerning (I) the adsorption of $\mathrm{CO}$ on $\mathrm{Ag}(001)$ [16] and (II) the observation of metal carbonyl formation on individual $\mathrm{Cu}$ and $\mathrm{Fe}$ adatoms on $\mathrm{Ag}(110)[10$, 14]. $\mathrm{CO}$ on $\mathrm{Ag}(001)$ is found to be very weakly bound and is still mobile at temperatures of $6 \mathrm{~K} \mathrm{[16].}$

In contrast to the $\mathrm{CO}$ adsorption behaviour observed so far for single adatoms and metal islands, where $\mathrm{CO}$ molecules are predominantly bound on top of the Au adatoms and to the rim of $\mathrm{Au}$ islands [20-22], we find two different configurations for a single Au adatom-one on top and the other one at the side of individual $\mathrm{Au}$ atoms on $\mathrm{Ag}(001)$. Moreover, IETS reveals different low-energy vibrational energies observed between tunneling voltages of 10 and $30 \mathrm{meV}$ for the two adsorption sites of $\mathrm{CO}$ to $\mathrm{Au}$ as compared to the one at $16 \mathrm{meV}$ for the single $\mathrm{CO}$ molecule bound to $\mathrm{Ag}(001)$. The latter value corresponds closely to the one reported previously [16], identified as the frustrated rotational mode of CO. DFT calculations of the adsorption energies, the diffusion barriers, and the vibrational frequencies of the $\mathrm{CO}$ molecule on the different adsorption sites contribute to a 
quantitative insight into the $\mathrm{CO}$ adsorption behaviour on single Au adatoms.

\section{Experimental and Computational Details}

The experiments have been performed in a home-built ultrahigh-vacuum (UHV) system equipped with a low-temperature scanning tunneling microscope (LT-STM) which operates at liquid He temperature (4 K). Moreover, low-energy electron diffraction (LEED), sample cleaning and gas dosing facilities are incorporated in the UHV chamber. The $\mathrm{Ag}(001)$ single crystal samples have been cleaned prior to $\mathrm{Au}$ deposition by several cycles of Ar sputtering at $800 \mathrm{eV}$ and annealing at $673 \mathrm{~K}$ in UHV. The sample cleanliness has been checked with STM. The Au atoms are deposited in situ at $5 \mathrm{~K}$ by ohmic heating of a gold coated filament located close to the STM head. CO molecules are dosed in situ at $12 \mathrm{~K}$ through a gas line which is brought near the sample via a movable manipulator. STM and IETS measurements are performed at $4.2 \mathrm{~K}$ utilizing $\mathrm{Pt}-\mathrm{Ir}$ tips. The differential conductance $d I / d V$ was measured using lock-in detection with a $2 \mathrm{mV}_{\mathrm{pp}}$ modulation at $6.56 \mathrm{kHz}$. The second derivative of the tunneling current has been obtained by numerical differentiation.

We have performed spin-polarized density functional theory (DFT) calculations as implemented in the GPAW package using a grid based basis set [23]. A grid spacing of $0.15 \AA$ was used in all calculations. The electron-electron interactions were treated using the PBE exchange-correlation functionals [24], while the electron occupations were smeared using the Fermi-Dirac expression with a smearing width of $0.1 \mathrm{eV}$ to aid convergence. To study the $\mathrm{Ag}(001)$ surface, we considered a $5 \times 5$ surface unit cell with four atomic layers and at least $8 \AA$ vacuum in the surface normal direction. For all calculations, the bottom two layers were fixed to bulk spacing while the top two layers and any adsorbate were allowed to optimize until forces on the atoms were less than $0.05 \mathrm{eV} / \AA$. Brillouin zone sampling was done using a $3 \times 3 \times 1 \mathrm{k}$-point mesh for all calculations. The energetic barriers for the diffusion of a $\mathrm{CO}$ molecule in the presence of an adsorbed $\mathrm{Au}$ atom on $\mathrm{Ag}(001)$ surface were calculated using the climbing-image nudged elastic band method [25].

\section{Results}

\subsection{Experimental Findings}

Figure 1a shows a typical STM topographic image, obtained with a CO terminated tip (see Fig. S1 in the Supplementary Material and [12]), after deposition of 0.005 monolayer (ML) of $\mathrm{Au}$ and $\mathrm{CO}$ onto a clean $\mathrm{Ag}(001)$ surface at $5 \mathrm{~K}$. CO
Fig. 1 STM and IETS measurements of $\mathrm{CO}$ and $\mathrm{Au}$ on $\operatorname{Ag}(001)$. a STM image of single $\mathrm{CO}$ molecules and $\mathrm{Au}$ atoms on $\mathrm{Ag}(001)$ at $4 \mathrm{~K}$. STM tunneling parameters: $I_{T}=100 \mathrm{pA}, V_{S}=30 \mathrm{mV}$, image size $8.1 \mathrm{~nm} \times 7.1 \mathrm{~nm}$. b sketch, identifying the species in image a. c IETS spectra taken at the locations indicated with crosses in $\mathbf{a}$ and $\mathbf{b}$ according to its corresponding color. See also Fig. S1 of the Supplementary Material
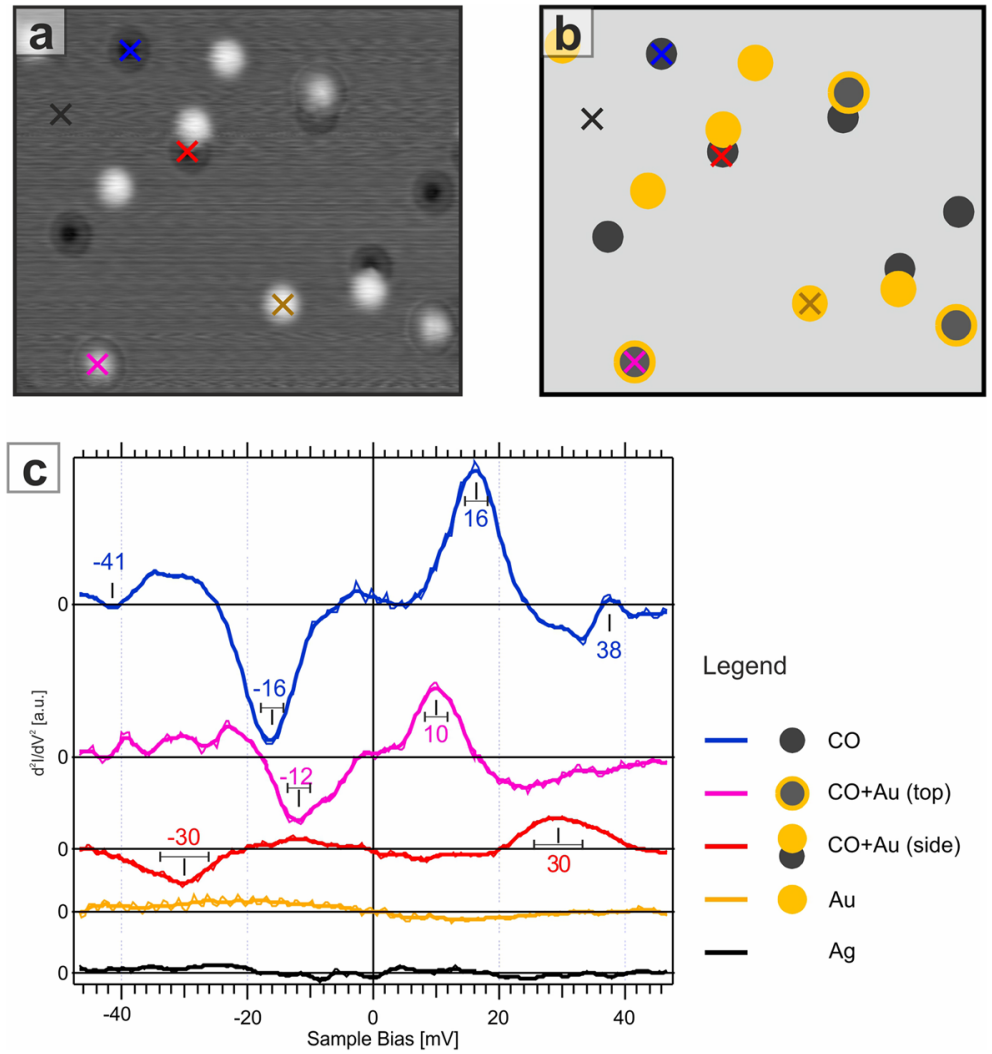
molecules appear as dark round depressions at a bias voltage below $100 \mathrm{mV}[12,26,27]$. The bright protrusions indicate the presence of the gold adatoms [20] with an apparent height of around $1.5 \AA$ at a bias voltage of $40 \mathrm{mV}$. They are distributed randomly over the surface. Moreover, alongside of three Au adatoms, dark depressions appear which are assumed to reflect the adsorbed $\mathrm{CO}$ molecules to the $\mathrm{Au}$ adatoms. In addition, two Au adatoms exhibit a halo which reflects the adsorption of a $\mathrm{CO}$ molecule on top of the $\mathrm{Au}$ adatom. Figure $1 \mathrm{~b}$ illustrates these observations in a simplified graphic with $\mathrm{CO}$ molecules (black) and Au adatoms (yellow) arranged according to their respective experimentally observed positions and contrasts shown in Fig. 1a. The crosses indicate the location of the STM tip during the IET spectroscopic measurements the results of which are displayed in Fig. 1c.

In addition to $\mathrm{Au}$ atoms with single co-adsorbed $\mathrm{CO}$ molecules, $\mathrm{Au}$ adatoms with two, three, and four laterally adsorbed $\mathrm{CO}$ molecules are observed as depicted in Fig. 2. Figure $2 \mathrm{a}-\mathrm{c}$ show the corresponding topographic images and Fig. 2d-f highlight the positions of the adsorbed Au adatoms and of the $\mathrm{CO}$ molecules with yellow and red circles, respectively. The distance between the centers of the red and yellow circles are found to be $6.0 \pm 0.3 \AA$. The angle between the line connecting these centers with respect to the nearest high symmetry orientation vectors of the $\operatorname{Ag}(001)$ substrate are found to be only either plus or minus $14^{\circ} \pm 1^{\circ}$, unless the number of co-adsorbed $\mathrm{CO}$ molecules is higher than four, which may happen with increasing $\mathrm{CO}$ coverage (see Supplementary Material Fig. S2).

Figure 1c summarizes the results of the IET spectroscopic measurements for the different measuring positions indicated in Fig. 1a, b. Figure 1c shows from bottom to top the IET spectra obtained on the clean $\operatorname{Ag}(001)$ surface (black, position indicated by the cross in the upper left of Fig. 1b), on a single Au adatom (yellow), on a Au adatom with a coadsorbed $\mathrm{CO}$ molecule (red), on a single Au adatom with a CO molecule on top of it (magenta), and on a single $\mathrm{CO}$ molecule on $\operatorname{Ag}(100)$ (blue). The spectra have been vertically displaced to provide better mutual distinction. They represent the second derivative of the average tunneling conductance $d I / d V$, obtained by summing up the signals of a voltage scan from -40 to $+40 \mathrm{mV}$ and vice versa, and subsequently applying a 5 point binominal smoothing.

The IET spectrum for the clean $\mathrm{Ag}(001)$ surface (bottom spectrum, black curve) is featureless, pointing to a metallic tip without a $\mathrm{CO}$ functionalization. With a $\mathrm{CO}$ functionalized tip the low-lying vibrational excitation observed for $\mathrm{CO}$ on $\mathrm{Ag}(001)$ (top spectrum, blue line) is present [16] (spectrum not shown). As expected, the IET spectrum obtained on top of a Au adatom (yellow) is also featureless within the chosen bias voltage range. However, the IET spectrum for a $\mathrm{CO}$ molecule adsorbed laterally to a Au adatom (red) exhibits a vibrational excitation around $30 \mathrm{meV}$, whereas the spectrum recorded on a Au adatom with a $\mathrm{CO}$ molecule adsorbed on top of it (magenta) shows a prominent vibrational excitation around $10 \mathrm{meV}$. Finally, for $\mathrm{CO}$ adsorption on the clean $\operatorname{Ag}(001)$ surface the IET spectrum (blue) displays a vibrational excitation around $16 \mathrm{meV}$. A comparison of these observed vibrational energies with the values and their interpretation in terms of the vibrational modes [internal stretching (IS), metal-C stretching (MC), frustrated rotation (FR), frustrated translation (FT)], reported in the existing literature, is presented in Table 1.

The value of $16 \mathrm{meV}$ for the FR mode of $\mathrm{CO}$ on $\operatorname{Ag}(001)$ is fully in line with the value reported in the literature [16]. The value for the FR mode of $\mathrm{CO}$ atop of a single $\mathrm{Au}$ on $\mathrm{Ag}(001)$ found in our experiment (around $10 \mathrm{meV}$ ) is nearest to the case of $\mathrm{CO}$ on single $\mathrm{Fe}$ atoms on $\mathrm{Ag}(110)$ where the $\mathrm{CO}$ molecule on top of the Fe atom is believed to have a slightly tilted on top configuration [14]. A qualitatively similar redshift to lower energy with respect to the case of $\mathrm{CO}$ on $\mathrm{Ag}(001)$ can be observed for the IS mode for $\mathrm{CO}$ adsorbed to a single $\mathrm{Au}$ atom on a
Fig. 2 STM measurements showing adsorption sites of $\mathrm{CO}$ at the side of $\mathrm{Au}$ atoms on $\operatorname{Ag}(001)$. STM tunneling parameters: a, d: $I_{T}=100 \mathrm{pA}$, $V_{S}=30 \mathrm{mV}$, and $\mathbf{b}, \mathbf{c}, \mathbf{e}, \mathbf{f}$ : $I_{T}=200 \mathrm{pA}, V_{S}=40 \mathrm{mV}$, image size all $2.0 \mathrm{~nm} \times 2.0 \mathrm{~nm}$. Yellow and red circles highlight the positions of the adsorbed $\mathrm{Au}$ adatoms and of the $\mathrm{CO}$ molecules, respectively
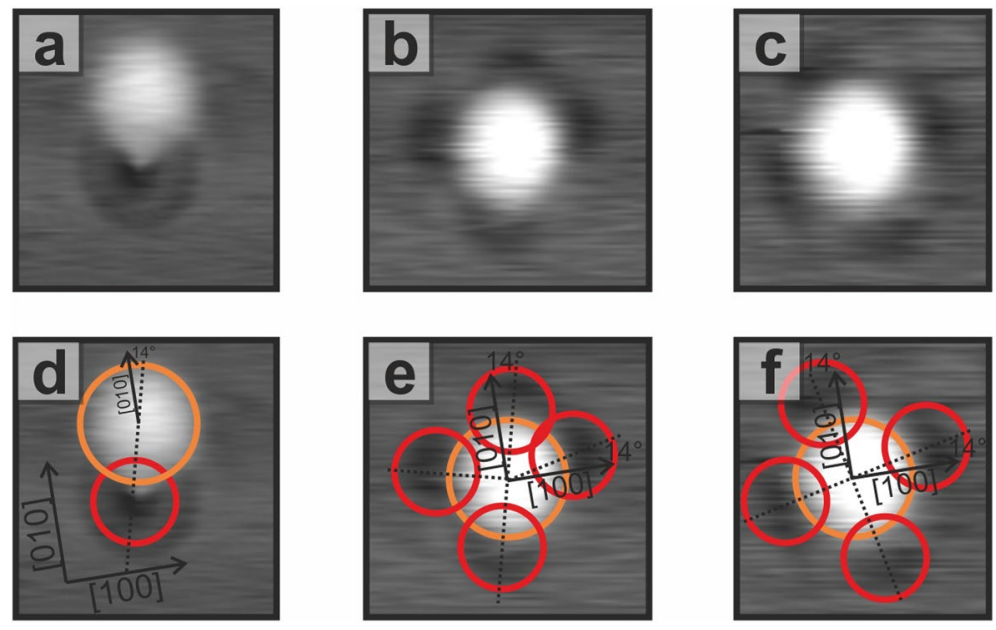
Table 1 Vibrational modes of $\mathrm{CO}(\mathrm{meV})$, depending on local environment: internal stretching (IS), metal-C stretching (MC), frustrated rotation (FR), frustrated translation (FT), as reported in the existing literature

\begin{tabular}{|c|c|c|c|c|c|}
\hline Vibrational modes of $\mathrm{CO}(\mathrm{meV})$ & IS & $\mathrm{MC}$ & FR & FT & References \\
\hline \multicolumn{6}{|l|}{ Experimental } \\
\hline Gas phase (1) & 266 & & & & {$[5]$} \\
\hline $\mathrm{On} \mathrm{Au}(110)$ & & & $31-33$ & $4-5$ & {$[28]$} \\
\hline On $\operatorname{Ag}(100)$ & & & $16 \pm 1$ & & This publication \\
\hline On $\operatorname{Ag}(100)$ & 263 & 33 & 16 & 5 & {$[16]$} \\
\hline On $\operatorname{Ag}(100)(2)$ & 256 & 51 & & & [29] \\
\hline On $\operatorname{Ag}(110)$ & & & 20 & & {$[10]$} \\
\hline On $\operatorname{Ag}(110)$ & & $31(2)$ & 19 & 8 & {$[30]$} \\
\hline On Pd(110) (0.1ML CO) (2) & 263 & 46 & & & {$[31]$} \\
\hline On Pd(110) (1.0ML CO) (2) & 248 & 48 & 42 & 9 & {$[31]$} \\
\hline On Ni(110) (2) & & & 48 & 8 & {$[32]$} \\
\hline On $\mathrm{Cu}(100)$ & 256 & 43 & 36 & 4 & {$[13,33,34]$} \\
\hline On $\mathrm{Cu}(100)$ & & & 35 & 5 & {$[35]$} \\
\hline On $\mathrm{Cu}(110)$ & 259 & & & & {$[36]$} \\
\hline On $\mathrm{Cu}(110)$ & 236 & & & $3-4(3)$ & {$[37,38]$} \\
\hline On $\mathrm{Cu}(111)$ & 241 & 58 & 35 & 5 & [39] \\
\hline On Fe(110) (2) & 234 & 57 & & & {$[40]$} \\
\hline On single $\mathrm{Au}$ on $\mathrm{NiAl}(110)$ & & & 35 & & [41] \\
\hline On single $\mathrm{Pd}$ on $\mathrm{NiAl}(110)$ & & & 40 & & {$[42]$} \\
\hline On single $\mathrm{Au}$ on $\mathrm{MgO} / \mathrm{Ag}(100)(1)$ & 230 & & & & {$[5]$} \\
\hline On $\mathrm{Au}$ clusters on $\mathrm{MgO} / \mathrm{Ag}(100)$ (1) & 263 & & & & {$[5]$} \\
\hline On single $\mathrm{Fe}$ on $\mathrm{Ag}(110)$ & 236 & & $10(4)$ & & [14] \\
\hline On single $\mathrm{Cu}$ on $\mathrm{Ag}(110)$ & 262 & & $36(32)(5)$ & & {$[14]$} \\
\hline On single $\mathrm{Au}$ on $\mathrm{Ag}(100)$ & & & $11 \pm 2$ & & This publication \\
\hline At the side of single $\mathrm{Au}$ on $\mathrm{Ag}(100)$ & & & $30 \pm 2$ & & This publication \\
\hline \multicolumn{6}{|l|}{ Theoretical } \\
\hline On Cu(100) & 249 & 47 & & 2.8 & [43] \\
\hline On $\mathrm{Cu}(100)$ & 245 & & $30(29)$ & & {$[35]$} \\
\hline On $\mathrm{Cu}(110)$ & 261 & 50 & $38(36)(6)$ & $8(7)(6)$ & {$[44]$} \\
\hline On $\mathrm{Cu}(111)$ & 246 & 47 & 33 & $2-6$ & {$[45]$} \\
\hline On $\operatorname{Ag}(100)$ & 254 & 27 & 17 & 4 & [16] \\
\hline On $\operatorname{Ag}(100)$ & 251 & 30 & $16-19$ & 3 & {$[43]$} \\
\hline On $\operatorname{Ag}(110)$ & 262 & 33 & $29(26)(6)$ & $9(8)(6)$ & [44] \\
\hline Gas phase & 266 & & & & This publication \\
\hline On $\operatorname{Ag}(100)$ & 253 & 28 & 19,23 & & This publication \\
\hline On single $\mathrm{Au}$ on $\mathrm{Ag}(100)$ & 248 & 36 & 11,19 & & This publication \\
\hline On $\mathrm{Ag}(100) 2 \mathrm{NN}$ atop at the side of single $\mathrm{Au}$ & 252 & 30 & 20,29 & & This publication \\
\hline On $\mathrm{Ag}(100) 3 \mathrm{NN}$ bridge at the side of single $\mathrm{Au}$ & 240 & 27 & 20,25 & & This publication \\
\hline
\end{tabular}

(1) Estimated from IR measurements. Units translated from $\mathrm{cm}^{-1}$ to $\mathrm{meV}\left(1 \mathrm{meV}=8.065 \mathrm{~cm}^{-1}\right)$. (2) Estimated from HREELS measurements. (3) Estimated from He atom scattering measurements, vibrational mode along the [001]([110]) direction. (4) Estimated from the drawn curve in the figure of the cited paper. The value is not mentioned within the text of the cited paper. (5) Value in parentheses from the negative bias range of IETS measurements. (6) Vibrational mode along the [001]([110]) direction
$\mathrm{MgO} / \mathrm{Ag}(001)$ island [5]. In all other cases presented here from literature the FR mode values are shifted to higher values - these values resemble the one found in our experiment for the case of $\mathrm{CO}$ adsorbing to the side of a Au atom on $\operatorname{Ag}(001)$.

\subsection{Computational Analysis}

Density functional theory (DFT) calculations have been performed to rationalize the experimental findings concerning the energetically preferred adsorption site of $\mathrm{Au}$ on a $\mathrm{Ag}(001)$ surface, the adsorption site of $\mathrm{CO}$ on $\mathrm{Ag}(001)$, 
the co-adsorption of a Au adatom and a $\mathrm{CO}$ molecule on $\operatorname{Ag}(001)$, the vibrational frequencies of different adsorption sites, and the diffusion of $\mathrm{CO}$ in the presence of a $\mathrm{Au}$ adatom on $\operatorname{Ag}(001)$.

The lattice constant for bulk $\mathrm{Ag}$ was calculated to be 4.17 $\AA$ in reasonably good agreement with the experimental value of $4.09 \AA$ [46]. A Au adatom prefers to bind to the hollow site on the $\operatorname{Ag}(001)$ surface with a binding energy of $-2.93 \mathrm{eV}$ (calculated with respect to the bare $\mathrm{Ag}$ surface and an isolated $\mathrm{Au}$ atom in gas phase). The adsorption at bridge and atop sites were found to be less stable with binding energies of $-2.28 \mathrm{eV}$ and $-1.92 \mathrm{eV}$, respectively.

A CO molecule, on the other hand, prefers to bind to the atop site on an Ag surface with a binding energy of $-0.26 \mathrm{eV}$ (calculated with respect to the bare Ag surface and an isolated $\mathrm{CO}$ molecule in gas phase). The adsorption at the bridge site is almost degenerate in energy with that at the atop site with binding energy of $-0.25 \mathrm{eV}$, while the adsorption at the hollow site is least preferred with a binding energy of $-0.19 \mathrm{eV}$. For the $\mathrm{CO}$ molecule adsorbed at the atop site on the Ag surface, we calculate vibrational frequencies corresponding to the IS mode $(253 \mathrm{meV}), \mathrm{MC}$ stretching mode $(28 \mathrm{meV})$ and two possible FR modes (19 meV and $23 \mathrm{meV}$ ). In agreement with the experiments, a red shift to lower energy is observed in the IS mode of $\mathrm{CO}$, on going from gas phase $(266 \mathrm{meV})$ to the adsorbed state $(253 \mathrm{meV})$.

Figure 3 shows five adsorption sites for a CO molecule and their respective binding energies on the $\operatorname{Ag}(001)$ surface in the presence of an adsorbed Au adatom, and the energy profile for the diffusion of the $\mathrm{CO}$ molecule between these sites. The binding energies (in black) are calculated with respect to an isolated $\mathrm{CO}$ molecule in gas phase and a $\mathrm{Au}$ adatom adsorbed (at the hollow site) on $\operatorname{Ag}(001)$. The numbers in black are according to the ordinate scale, while the numbers in red are the energy barriers for the forward process for every individual diffusion step.

The binding energies suggest that sites around $\mathrm{Au}$, where $\mathrm{CO}$ is in fourth nearest neighbor (4NN), third nearest neighbor $(3 \mathrm{NN})$, or second nearest neighbor $(2 \mathrm{NN})$ positions, are degenerate in energy and are comparable to the binding energy of $\mathrm{CO}$ on a bare $\mathrm{Ag}(001)$ surface $(-0.26 \mathrm{eV})$, i.e., the $\mathrm{CO}$ molecules at these sites do not feel the presence of the Au adatom. The adsorption of $\mathrm{CO}$ at the first nearest neighbor ( $1 \mathrm{NN}$ ) atop $\mathrm{Ag}$ position is less stable with a binding strength of $-0.18 \mathrm{eV}$. The experimental STM measurements do not show the presence of $\mathrm{CO}$ molecules on the $\mathrm{Ag}$ surface closer to $\mathrm{Au}$ than the $4 \mathrm{NN}$ bridge site position.

However, the different experimental vibrational spectra as well as the corresponding DFT calculations [for $\mathrm{CO}$ on $\operatorname{Ag}(001)$ : calculated values $(\mathrm{meV})=19,23$ and for $\mathrm{CO}$ on $\mathrm{Ag}(001)$ near a $\mathrm{Au}$ adatom: calculated values 20, 25 and $29 \mathrm{meV}$ ] underline that the dynamical properties, i.e., the vibrational properties of the $\mathrm{CO}$ molecule are slightly different for the $\mathrm{CO}$ on $\mathrm{Ag}(001)$ and the $\mathrm{CO}$ near a Au adatom on $\operatorname{Ag}(001)$. This fact indicates that the Au adatom with its contribution to the local density of states is somehow in contact with the $\mathrm{CO}$ molecule. In a similar way, the interaction of $\mathrm{CO}$ molecules with surface state electrons on $\mathrm{Ag}(111)$ has revealed a preferred adsorption at $5 \mathrm{~K}$ near the minima of the standing wave pattern [47].

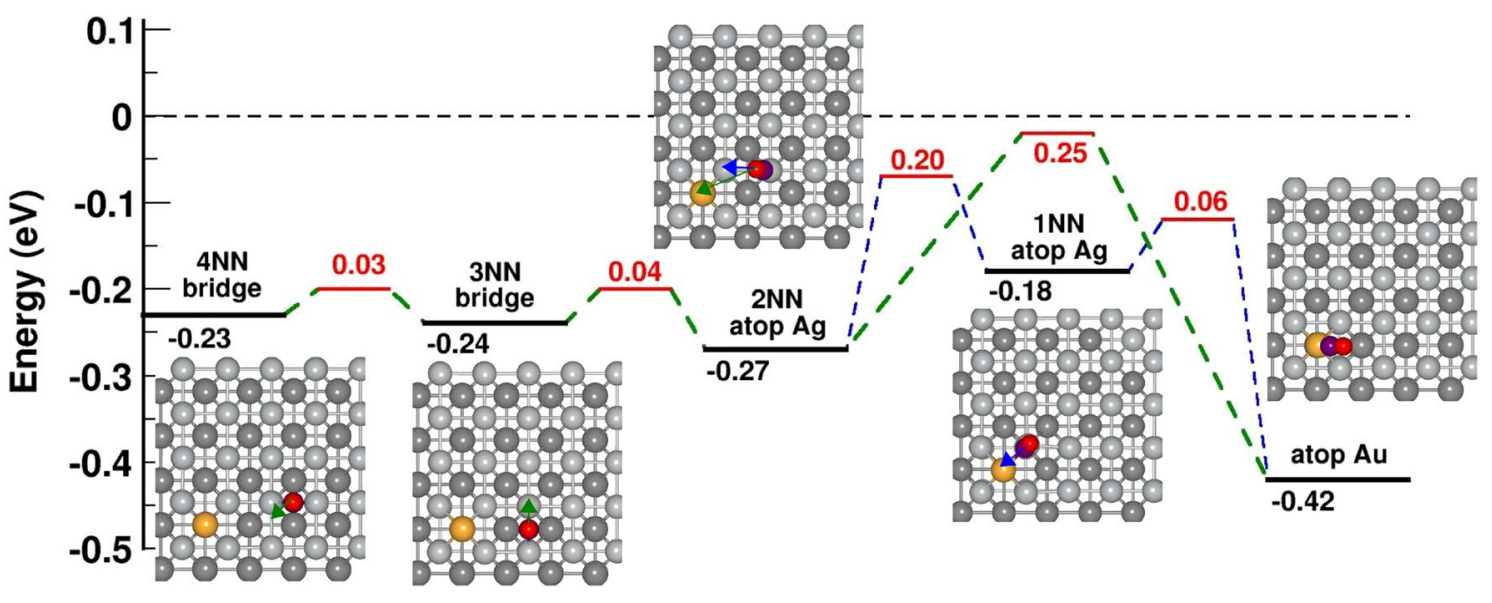

Fig. 3 Energy profile for the diffusion (green/blue arrows) of $\mathrm{CO}$ on the $\operatorname{Ag}(001)$ surface in the presence of an adsorbed Au adatom. The energy scale is referenced to the sum of the total energies of a $\mathrm{CO}$ molecule in gas phase and $\operatorname{Au} / \operatorname{Ag}(001)$ surface, i.e. $E_{\text {tot }}(\mathrm{CO})+E_{\text {tot }}$ $[\mathrm{Au} / \mathrm{Ag}(001)]=0$. Numbers in red represent the energy barriers for individual diffusion steps in the forward direction. The atoms $\mathrm{C}, \mathrm{O}$ and $\mathrm{Au}$ are shown in purple, red and yellow colors, respectively. The $\mathrm{Ag}$ atoms on the top and second layers of the surface are shown in light and dark gray colors, respectively. We show the diffusion of $\mathrm{CO}$ from the fourth nearest neighbor (4NN) bridge site to the third nearest neighbor ( $3 \mathrm{NN})$ bridge site to the second nearest neighbor $(2 \mathrm{NN})$ atop site. From the $2 \mathrm{NN}$ atop $\mathrm{Ag}$ site it can diffuse to the atop $\mathrm{Au}$ position, directly, or via a first nearest neighbor (1NN) atop $\mathrm{Ag}$ site. All neighboring positions are counted with respect to the position of the adsorbed $\mathrm{Au}$ atom 
Additional electronic multimedia files (mpg) showing the frustrated rotation vibrational modes and frequencies for the $\mathrm{CO}$ molecule adsorbed (i) on the bare Ag surface, (ii) on top of an adsorbed $\mathrm{Au}$ atom on the $\mathrm{Ag}$ surface and (iii/iv) to the side of an adsorbed $\mathrm{Au}$ atom on the Ag surface, are given in the Supplementary Material. The energy barriers for the diffusion of $\mathrm{CO}$ over the $\mathrm{Ag}$ surface from $4 \mathrm{NN}$ bridge site to $3 \mathrm{NN}$ bridge site to $2 \mathrm{NN}$ atop site are very low $(0.03$ to $0.04 \mathrm{eV})$. The $\mathrm{CO}$ at the $2 \mathrm{NN}$ atop site can diffuse to the most energetically preferred adsorption site, atop Au position via two pathways, viz., (i) $2 \mathrm{NN}$ atop $\mathrm{Ag} \rightarrow$ atop $\mathrm{Au}$ with a barrier of $0.25 \mathrm{eV}$ or (ii) $2 \mathrm{NN}$ atop $\mathrm{Ag} \rightarrow 1 \mathrm{NN}$ atop $\mathrm{Ag} \rightarrow$ atop $\mathrm{Au}$ with barriers $0.20 \mathrm{eV}$ and $0.06 \mathrm{eV}$, respectively. This suggests that the $\mathrm{CO}$ molecules have to overcome a high barrier in order to reach the atop Au position. This may not be possible at the low temperatures of the experiment. We suggest that the direct adsorption by gas-phase deposition or tip assisted diffusion of $\mathrm{CO}$ [48] are two possible explanations for the existence of the $\mathrm{CO}$ molecules on top of $\mathrm{Au} / \mathrm{Ag}(001)$.

\section{Discussion}

The very low-diffusion barriers for $\mathrm{CO}$ on $\mathrm{Ag}(001)$ together with tip-assisted diffusion are most probably the reason for the experimentally observed agglomeration of $\mathrm{CO}$ molecules around $\mathrm{Au}$ adatoms, as shown in Fig. 2. The calculated vibrational frequencies for $\mathrm{CO}$ adsorbed on bare $\mathrm{Ag}$ and that adsorbed to the side of Au are almost the same, i.e., DFT does not find a difference between these two sites, which is also evidenced by the results of the binding energies for the two sites. The vibrational frequencies of $\mathrm{CO}$ on top of $\mathrm{Au}$ are different. Our calculations predict for the three cases [CO on $\mathrm{Ag}, \mathrm{CO}$ on $\mathrm{Au}$ (top)/Ag, and $\mathrm{CO}$ on $\mathrm{Au}$ (side)/Ag] 8 distinct IS, MC, and FR vibrational modes. In the experiment, however, only one mode (MC or FR, see Table 1) is observed for each adsorbate configuration.

The IETS selection rules depend strongly on the local density of states induced by the adsorbates at the Fermi level and on the local symmetry [49]. We speculate that in the $\mathrm{CO} / \mathrm{Ag}$ case only the FR mode at $19 \mathrm{meV}$ is observed, in the case of $\mathrm{CO}$ adsorbed on top of a Au atom only the 11 meV FR mode is seen, and on $\mathrm{CO}$ adsorbed at the side of $\mathrm{Au}$ the $30 \mathrm{meV}(\mathrm{MC})$ and/or $29 \mathrm{meV}$ (FR) modes are present. With these assumptions a nearly quantitative correspondence between measured and calculated vibrational frequencies is obtained.

\section{Conclusions}

To summarize, the binding behaviour of a $\mathrm{CO}$ molecule to a $\mathrm{Au}$ adatom on a $\mathrm{Ag}(001)$ surface has been investigated by low-temperature STM and IETS. In addition to the binding site of the $\mathrm{CO}$ molecule on bare $\operatorname{Ag}(001)$, two different binding configurations of the $\mathrm{CO}$ molecule have been identified, one atop of a Au adatom and another one laterally adsorbed to a Au adatom. Both configurations exhibit different frustrated rotational vibrational frequencies detected with local IET spectroscopy. The measured vibrational frequency for $\mathrm{CO} / \mathrm{Ag}(001)$ confirms earlier results, reported in Table 1. Theoretical modeling with DFT concerning the adsorption energies, the diffusion barriers, and the vibrational frequencies of the $\mathrm{CO}$ molecule on the different binding sites rationalizes the experimental findings. The chemical verification and identification of atomic species by IETS is a very powerful tool and although first measurements have already been shown by Stipe et al. [8] more than 20 years ago, this method is still not fully established and should be applied to many more examples. The present study enlarges our knowledge about the characteristics of molecular binding sites at the atomic level.

Acknowledgements Open access funding provided by Projekt DEAL. The theoretical work was supported by the Academy of Finland through Projects 319208 (H.H.) and 277222 (K.H.). Computations were made at the Barcelona Supercomputing Center as part of a PRACE Project 2018194723 and at the JYU Node of the FGCI Infrastructure (Persistent Identifier urn:nbn:fi:research-infras-2016072533).

\section{Compliance with Ethical Standards}

Conflict of interest The authors declare that they have no conflict of interest.

Open Access This article is licensed under a Creative Commons Attribution 4.0 International License, which permits use, sharing, adaptation, distribution and reproduction in any medium or format, as long as you give appropriate credit to the original author(s) and the source, provide a link to the Creative Commons licence, and indicate if changes were made. The images or other third party material in this article are included in the article's Creative Commons licence, unless indicated otherwise in a credit line to the material. If material is not included in the article's Creative Commons licence and your intended use is not permitted by statutory regulation or exceeds the permitted use, you will need to obtain permission directly from the copyright holder. To view a copy of this licence, visit http://creativecommons.org/licenses/by/4.0/.

\section{References}

1. Bäumer M, Freund HJ (1999) Prog Surf Sci 61(7):127

2. Haruta M (1997) Catal Today 36(1):153

3. Valden M, Lai X, Goodman DW (1998) Science 281(5383):1647

4. Sanchez A, Abbet S, Heiz U, Schneider WD, Häkkinen H, Barnett RN, Landman U (1999) J Phys Chem A 103(48):9573

5. Sterrer M, Yulikov M, Risse T, Freund HJ, Carrasco J, Illas F, Di Valentin C, Giordano L, Pacchioni G (2006) Angew Chem Int Ed 45(16):2633

6. Risse T, Shaikhutdinov S, Nilius N, Sterrer M, Freund HJ (2008) Acc Chem Res 41(8):949 
7. Schneider WD, Heyde M, Freund HJ (2018) Chem Eur J 24(10): 2317

8. Stipe BC, Rezaei MA, Ho W (1998) Science 280(5370):1732

9. Stipe BC, Rezaei MA, Ho W (1999) Phys Rev Lett 82(8):1724

10. Ho W (2002) J Chem Phys 117(24):11033

11. Reed MA (2008) Mater Today 11(11):46

12. Bartels L, Meyer G, Rieder KH (1997) Appl Phys Lett 71(2):213

13. Lauhon LJ, Ho W (1999) Phys Rev B 60:R8525

14. Lee H, Ho W (2000) Phys Rev B 61(24):R16347

15. Heinrich AJ, Lutz CP, Gupta JA, Eigler DM (2002) Science 298(5597): 1381

16. Arafune R, Shin HJ, Jung J, Minamitani E, Takagi N, Kim Y, Kawai M (2012) Langmuir 28(37): 13249

17. Shirman T, Lattimer J, Luneau M, Shirman E, Reece C, Aizenberg M, Madix RJ, Aizenberg J, Friend CM (2018) Chem Eur J 24(8): 1833

18. Pia G, Sogne E, Falqui A, Delogu F (2018) Sci Rep 8(1):15208

19. Zugic B, van Spronsen MA, Heine C, Montemore MM, Li Y, Zakharov DN, Karakalos S, Lechner BA, Crumlin E, Biener MM, Frenkel AI, Biener J, Stach EA, Salmeron MB, Kaxiras E, Madix RJ, Friend CM (2019) J Catal 380:366

20. Yang B, Lin X, Gao HJ, Nilius N, Freund HJ (2010) J Phys Chem C 114(19):8997

21. Wallis TM, Nilius N, Ho W (2016) J Phys Chem Lett 7(22):4683

22. Nilius N, Risse T, Sterrer M, Shaikhutdinov S, Freund HJ (2014) Structure and bonding, vol 162. Springer, Cham, p 91

23. Enkovaara J, Rostgaard C, Mortensen JJ, Chen J, Dułak M, Ferrighi L, Gavnholt J, Glinsvad C, Haikola V, Hansen HA, Kristoffersen HH, Kuisma M, Larsen AH, Lehtovaara L, Ljungberg M, Lopez-Acevedo O, Moses PG, Ojanen J, Olsen T, Petzold V, Romero NA, Stausholm-Møller J, Strange M, Tritsaris GA, Vanin M, Walter M, Hammer B, Häkkinen H, Madsen GKH, Nieminen RM, Nørskov JK, Puska M, Rantala TT, Schiøtz J, Thygesen KS, Jacobsen KW (2010) J Phys Condens Matter 22(25):253202

24. Perdew JP, Burke K, Ernzerhof M (1996) Phys Rev Lett 77:3865

25. Henkelman G, Uberuaga BP, Jónsson H (2000) J Chem Phys 113:9901

26. Niemi E, Nieminen J (2004) Chem Phys Lett 397(1):200

27. Nieminen JA, Niemi E, Rieder KH (2004) Surf Sci 552(1):L47
28. Xu C, Chiang CL, Han Z, Ho W (2016) Phys Rev Lett 116:166101

29. Burghaus U, Vattuone L, Gambardella P, Rocca M (1997) Surf Sci 374(1-3): 1

30. Oh J, Lim H, Arafune R, Jung J, Kawai M, Kim Y (2016) Phys Rev Lett 116:056101

31. Kato H, Kawai M, Yoshinobu J (1999) Phys Rev Lett 82:1899

32. Voigtländer B, Bruchmann D, Lehwald S, Ibach H (1990) Surf Sci 225(1): 151

33. Andersson S (1979) Surf. Sci. 89(1):477

34. Arafune R, Hayashi K, Ueda S, Uehara Y, Ushioda S (2006) Surf Sci 600(18):3536

35. Pascual JI (2005) Eur Phys J D 35(2):327

36. Woodruff D, Hayden B, Prince K, Bradshaw A (1982) Surf Sci 123(2):397

37. Lee HJ, Ho W (1999) Science 286(5445):1719

38. Braun J, Weckesser J, Ahner J, Mocuta D, Yates JT, Wöll C (1998) J Chem Phys 108(13):5161

39. Vitali L, Ohmann R, Kern K, Garcia-Lekue A, Frederiksen T, Sanchez-Portal D, Arnau A (2010) Nano Lett 10(2):657

40. Erley W (1981) J Vac Sci Technol 18(2):472

41. Wallis TM, Nilius N, Ho W (2003) J Chem Phys 119(4):2296

42. Nilius N, Wallis TM, Ho W (2002) J Chem Phys 117(24): 10947

43. Ortigoza MA, Rahman TS, Heid R, Bohnen KP (2010) J Phys Condens Matter 22:39

44. Lorente N, Ueba H (2005) Eur Phys J D 35(2):341

45. Rossen ETR, Flipse CFJ, Cerdá JI (2013) Phys Rev B 87:235412

46. Kittel C (1953) Introduction to solid state physics. Wiley, Hoboken

47. Kulawik M, Rust HP, Heyde M, Nilius N, Mantooth B, Weiss P, Freund HJ (2005) Surf. Sci. 590(2):L253

48. Li J, Berndt R, Schneider WD (1996) Phys Rev Lett 76(11):1888

49. Lorente N, Persson M, Lauhon LJ, Ho W (2001) Phys Rev Lett 86(12):2593

Publisher's Note Springer Nature remains neutral with regard to jurisdictional claims in published maps and institutional affiliations. 